\title{
A Causal Model of Parents' Personality Traits and Academic Performance with the Mediating Role of Academic Buoyancy
}

Iranian Evolutionary and Educational Psychology Journal September 2020: 200-207 (C) University of Hormozgan Publication 2020 DOI: 10.29252/ieepj.2.3.200 http://ieepj.hormozgan.ac.ir

\author{
Mansour Soheili ${ }^{1}$, Soltanali Kazemi*, Nadereh Sohrabi Shekofti ${ }^{3}$, Majid Barzegar ${ }^{3}$
}

\begin{abstract}
This study aimed to present a relationship model between parenting styles and parental personality traits and academic performance with the mediating role of academic buoyancy in high school students. The study was a descriptive correlation and its statistical population included all male and female high school students in Fasa in the academic year of 2018-19 and their parents, among whom using a multi-stage cluster random sampling method. A total of 493 students (248 boys and 245 girls) were selected and the data were collected using NEO_FFI Five Personality Factor Scale, Academic Performance Scale, and Academic Buoyancy Scale. Findings from structural equation modeling showed that academic buoyancy mediates the relationship between personality traits and academic performance. The study model predicted $46 \%$ of the variance changes in the criterion variable. Examining the fit of the model through the fit indices showed a suitable and acceptable fit of the model.
\end{abstract}

Keywords: Personality Traits, Academic Buoyancy, Academic Performance

\section{Introduction}

The success and academic performance of students in any society indicate the success of the educational system in the field of goal setting and attention to meeting individual needs. Therefore, the educational system can be considered efficient and successful when the academic performance of its students in different courses has the highest and highest figure. Nowadays, researchers have a special emphasis on the need to pay attention to the predictors of academic success, as in the last three decades, the study of factors affecting academic performance has received more attention than educational systems (Ghorbani, Zahrakar, \& Mohsenzadeh, 2020). MacCann et al. (2020) argue that accurate prediction of academic performance is not based solely on the competencies measured by intelligence tests, but also on information about personality, motivational-emotional, and cognitive traits that play a mediating role. In this regard, due to the relationship between cognition, motivation, and emotion in human behavior, several variables have been developed and tested to explain students' academic performance and academic achievement in different academic areas (Walters \& Pintrich). Academic

1. PhD Student, Department of Psychology, Islamic Azad University, Marvdasht Branch, Marvdasht, Iran

2. Associate Professor, Department of Psychology, Islamic Azad University, Marvdasht Branch, Marvdasht, Iran

*Corresponding author email: kazemi-edu@yahoo.com

3. Assistant Professor, Department of Psychology, Islamic Azad University, Marvdasht Branch, Marvdasht, Iran

4. Assistant Professor, Department of Psychology, Islamic Azad University, Marvdasht Branch, Marvdasht, Iran 
performance affects important aspects of people's lives such as promotion to higher education, getting a better job, better social status, more satisfaction, etc. (Galla et al., 2014). Among these, the role of antecedents and factors affecting academic performance should also be considered and it seems that one of the antecedents of academic performance is academic buoyancy, which can also be examined concerning their personality traits. The concept of academic buoyancy has been proposed by Martin and Marsh (2009) as a method of examining constructive and positive reactions to a variety of barriers experienced by students in the current academic year or schools, such as high-risk exam pressures, poor grades, etc. Martin and Marsh (2009) argue because resilience specifically refers to individuals' capacity to respond constructively to major academic challenges and barriers; its application is limited to the challenges and difficulties that are specific to the daily academic life of the majority of students. The results of numerous studies show that academic buoyancy, which reflects academic resilience in the context of positive psychology, is a factor (Collie et al., 2017; Miller, Connolly, \& Maguire, 2013; Putwain, Wood, \& Pekrun, 2020). This affects the ability to deal with the challenges and obstacles of daily academic life (Colmar, Liem, Connor, \& Martin, 2019; Martin \& Marsh, 2020; Rezaei Gazki, Delavar, \& Samavi, 2019).

Personality is an "abstract concept," meaning that it is something like the energy in physics that is not observable but is inferred through a combination of behavior, thoughts, motivation, emotion, and so on. Personality makes the difference between all people (humans) from each other. But these differences are only in some "features and characteristics". Freud considers personality to be a combination of the three elements of "institution, self, transcendence." (Mayer, 2007) considers personality as a dynamic organization of the perceptual, passive, voluntary, and physical aspects of man. Personality traits are a precursor to academic performance and academic buoyancy. Motowidlo, Hooper, and Jackson (2006) believe that personality traits can predict situational behaviors. These traits interact with situations and the environment. This determines the behavior and how you interact with others. Due to this, we expect that the way people interact and communicate with others, like many other activities, will be influenced by their personality. The effect of personality dimensions on behavior and cognition causes behavioral, cognitive or non-cognitive consequences in such a way that it has a significant effect on the rate of academic buoyancy and subsequently in the organization and implementation of education programs and students' treatment of current academic challenges (Bauer \& Liang, 2003). Parents' personality traits can also determine their educational status and performance due to their children's close relationship with them. Many of a child's personality traits are influenced by parental personality traits. Parents raise their children in different ways based on their cultural patterns and ideals. In many educational and professional environments and situations, individual abilities are emphasized as the main factor of success, but it should be noted that abilities alone cannot be a factor of success, but individual differences between individuals should be considered as important and effective factors in the job and academic success of individuals (Poropat, 2014). A review of the research background shows that there is a significant relationship between personality traits and academic performance (Chamorro $\square$ Premuzic \& Furnham, 2003; Hakimi, Hejazi, \& Lavasani, 2011; Hazrati-Viari, Rad, \& Torabi, 2012). Furthermore, there is a relationship between personality traits and academic buoyancy (Martin, 2013; Martin, Colmar, Davey, \& Marsh, 2010; Putwain, Connors, Symes, \& Douglas-Osborn, 2012) as well as academic buoyancy and academic performance (Martin, 2014; Putwain \& Daly, 2013; Putwain, Daly, Chamberlain, \& Sadreddini, 2016).

The importance of the mentioned findings on the one hand and the lack of studies related to the interactive 
study of these variables in the educational context of the country, on the other hand, has been the most important motivator for the present study. In this regard, an attempt was made to investigate and explain the mediating role of academic buoyancy in the relationship between parents 'personality traits and students' academic performance. Therefore, the hypothesis of the present study has been expressed and examined in the following format: Academic buoyancy plays a significant mediating role in the relationship between parental personality traits and academic performance in high school students.

\section{Material and Method}

The present research design is a descriptive correlation in which the hypothetical relationships between the variables of the research model in the form of structural equation methods have been investigated. In this study, personality traits play a role as an exogenous variable, academic buoyancy as a mediating variable, and academic performance as an endogenous variable. The statistical population of this study was all male and female high school students in Fasa in the academic year of 2018-19 who were studying in high schools in Fasa. To estimate the sample using a multistage cluster random sampling method, 493 students (248 girls and 245 boys) were selected as a statistical sample. Out of 14 boys 'schools and 14 girls' schools in Fasa, four girls 'schools and four boys' schools were randomly selected and two classes were selected from each school. Students in selected classes were the sample size, and the parents of the same students also participated in the statistical sample.

After collecting the scales, statistical analysis was performed on data from 493 people ( 245 boys and 248 girls) as a final sample. The following scales were used to collect data.

A) Five-factor personality scale NEO_FFI: NEO questionnaire is one of the newest questionnaires related to the evaluation of personality construction based on the perspective of factor analysis. In terms of reflecting the 5 main factors, this test is considered as a comprehensive model based on factor analysis today and its wide application in evaluating the personality of healthy people as well as in clinical affairs can be one of the most appropriate tools for evaluating personality. The NEOPI-R Personality Questionnaire replaces the NEO test developed in 1985 by McCreery and Costa. This questionnaire measures 5 main personality factors and 6 characteristics in each factor or other words 30 characteristics. In the standardization of the NEO test, which was performed by Grossi Farshi (Joshanloo, Daemi, Bakhshi, Nazemi, \& Ghafari, 2010) on a sample of 2000 students from Tabriz, Shiraz, and medical universities of these two cities, the correlation coefficient of the 5 main dimensions was between 0.56 and 0.87 has been reported. Cronbach's alpha coefficients in each of the main factors of penness to Experience, Conscientiousness, Extraversion/Introversion, Agreeableness, and Neuroticism were $0.86,0.73,0.56,0.68$, and 0.87 , respectively. To evaluate the content validity of this test, the correlation between the two forms of the personal report (S) and the observer evaluation form (R) was used. The maximum correlation was 0.66 in the extraversion factor and the minimum was 0.45 in the adjustment factor cited by Grossi Farshi (Joshanloo et al., 2010). In the present study, the reliability of this scale was determined by calculating Cronbach's alpha, the value of which was 0.89 for irritability, 0.81 for extroversion, 0.75 for openness, 0.78 for compatibility, and 0.91 for conscientiousness.

B) Academic Performance Scale: To measure academic performance, the academic performance test in the Dortaj, Mousavi, and Rezaei (2013) has been used. This test has 48 questions. Some questions affect only one factor while others affect more than one factor. This questionnaire measures five factors of self-efficacy, 
emotional effects, planning, lack of outcome control, and motivation. The reliability of this test was obtained by Dortaj et al. (2013) by the internal consistency method (Cronbach's alpha, 0.73 ). The degree of reliability obtained in each of the areas related to academic performance is the first factor (0.92), the second factor $(0.93)$, the third factor (0.73), the fourth factor $(0.74)$, and the fifth factor (0.72). In the present study, the reliability of this questionnaire was determined by calculating Cronbach's alpha, the value of which was 0.92 for the whole scale, 0.84 for self-efficacy, 0.91 for planning, 0.88 for emotional effects, and 0.82 for lack of outcome control and 0.79 was obtained for the motivation component.

C) Academic Buoyancy Scale: Martin (2013) Academic Buoyancy Scale were used to measure the Academic Buoyancy Scale. The responses on the Martin and Marsh (2009) scale are calculated on a 7-point Likert scale (strongly disagree 1, strongly agree 7). The Martin and Marsh scales were stable in terms of internal consistency and retesting (Cronbach's alpha, 0.80, and retest, 0.67). In Iran, Cronbach's alpha coefficients obtained by deleting item 8 were equal to 0.80 and the retest coefficient was equal to 0.73 . Also, the correlation range of items with the total score is 0.51 to 0.68 (Jahedizadeh, Ghonsooly, \& Ghanizadeh, 2019). In the present study, the reliability of this questionnaire was determined by calculating Cronbach's alpha, the value of which was 0.87 for the whole scale. Note that the conditions of the research were explained to all participants in the research and after obtaining their permission; their answers were used as the main data in this research.

\section{Results}

In this section, first, the descriptive findings of the research variables and then the model test results are presented. Descriptive findings related to the mean, standard deviation, minimum and maximum scores of the subjects on the research variables are shown in Table 1.

Table 1. Descriptive findings related to research variables in the sample

\begin{tabular}{|l|c|c|c|c|}
\hline Variable & Mean & SD & Min. & Max. \\
\hline Academic Buoyancy & 38.45 & 2.58 & 32 & 45 \\
\hline Planning & 59.40 & 6.20 & 28 & 70 \\
\hline Lack of Outcome Control & 11.84 & 2.81 & 5 & 18 \\
\hline Emotional Effects & 23.83 & 5.90 & 8 & 37 \\
\hline Motivation & 52.72 & 5.22 & 21 & 65 \\
\hline Efficacy & 31.20 & 3.35 & 15 & 38 \\
\hline Neurosis & 21.37 & 6.73 & 12 & 38 \\
\hline Extroversion-Introversion & 46.04 & 4.86 & 32 & 60 \\
\hline New Experiences & 46.04 & 4.70 & 33 & 60 \\
\hline Agreeableness & 46.03 & 4.92 & 33 & 60 \\
\hline Conscientiousness & 45.98 & 4.68 & 33 & 60 \\
\hline
\end{tabular}

$\mathrm{N}=493$

Results revealed the highest correlation coefficient is related to the liberal style with extroverted introversion (0.92) and the lowest correlation coefficient is related to the lack of outcome control with new experiences (0.14). To use the structural equation modeling method, first, the assumptions were examined and the missing data were restored by the data replacement method with the mean of the variable. They were not above or below the mean, and to examine the multivariate outlier data, the Mahalanobis distance was calculated 
along with the significance level for the observed variables. Kolmogorov-Smirnov Test was used to check the normality of the data. Considering that the significance level values in all variables were higher than 0.05 , the normality of the research variables was ensured. Tables 2 and 3 present the parameters for measuring the direct relationships of the variables in the whole sample and the suitability indicators of the research model.

Table 2. Parameters for measuring the direct relationships of variables in the whole sample

\begin{tabular}{|l|c|c|c|c|c|}
\hline \multicolumn{1}{|c|}{ Path } & Beta & B & Standard Error & Sig. & Result \\
\hline Personality traits to academic buoyancy & 0.76 & 0.49 & 0.023 & 0.01 & Confirmed \\
\hline Personality traits to academic performance & 0.36 & 0.18 & 0.03 & 0.01 & Confirmated \\
\hline Academic buoyancy to academic performance & 0.52 & 0.40 & 0.054 & 0.01 & Confirmated \\
\hline
\end{tabular}

According to the reported fit indices, CMIN/DF index (3.61) is less than 5, the RMSEA index with a value of 0.072 is less than 0.08 , and the GFI, AGFI, NFI, CFI, and IFI indices are higher than 0.9 which indicated a good consistency level. The direct relationships of the variables in table 2 show the standard coefficients of personality traits to academic buoyancy $(\beta=0.76, \mathrm{P}<0.01)$, personality traits to academic performance $(\beta=0.36, \mathrm{P}<0.01)$, and academic buoyancy to academic performance $(=(\beta=0.52, \mathrm{P}<0.01)$ is positive and significant. To examine the indirect relationships of variables was done through the bootstrap method. Table 3 shows the mediation test of the indirect relationships between the variables of parental personality traits and academic performance based on the mediating variable of academic buoyancy by the bootstrap method.

Table 3. Indirect mediation test of parental personality trait variables with academic performance based on the mediator of academic buoyancy variable

\begin{tabular}{|c|c|c|c|c|c|c|}
\hline Path & Data & Bootstrap & Bias & Error & Low Limit & Upper Limit \\
\hline $\begin{array}{l}\text { Parents' personality traits to academic performance } \\
\text { through academic buoyancy }\end{array}$ & 0.821 & 0.080 & 0.0019 & 0.0271 & 0.028 & 0.138 \\
\hline Neurosis to academic performance through buoyancy & 0.059 & -0.061 & -0.0017 & 0.0817 & -0.223 & 0.110 \\
\hline $\begin{array}{l}\text { Extroverted Introversion to academic performance } \\
\text { through academic buoyancy }\end{array}$ & 0.355 & 0.0351 & -0.0045 & 0.0815 & 0.227 & 0.563 \\
\hline $\begin{array}{l}\text { New experiences to academic performance through } \\
\text { academic buoyancy }\end{array}$ & 0.105 & 0.082 & -0.0233 & 0.1734 & 0.227 & 0.358 \\
\hline $\begin{array}{l}\text { Adaptability to academic performance through aca- } \\
\text { demic buoyancy }\end{array}$ & 0.233 & 0.216 & -0.0173 & 0.1549 & 0.106 & 0.498 \\
\hline $\begin{array}{l}\text { Conscientiousness to academic performance through } \\
\text { academic buoyancy }\end{array}$ & 0.168 & 0.153 & -0.0150 & 0.1657 & 0.172 & 0.475 \\
\hline
\end{tabular}

The results of Table 3 revealed that the indirect relationship between personality traits and academic performance through academic buoyancy does not include zero. Therefore, the research hypothesis is confirmed. In other words, the variable (academic buoyancy) mediates the relationship between the exogenous variable (personality traits) and the endogenous variable (academic performance).

\section{Discussion}

The present study was conducted to investigate the mediating role of academic buoyancy in the relationship between personality traits and academic performance of high school students. In this regard, the findings of data analysis by structural equation method indicated that academic buoyancy mediates the relationship between exogenous variables (parental personality traits) and academic performance. This finding is consistent 
with the earlier studies (Hazrati-Viari et al., 2012; Martin, 2013, 2014; Martin et al., 2010). In general, personality traits such as positive self-concept, sociability, intelligence, adequacy in educational work, self-regulation and self-regulation, self-esteem, good communication, mental and physical health, and problem-solving skills are among the factors affecting the increase of academic buoyancy. Therefore, we can expect that if students have high positive personality traits and low negative personality traits, they will be better able to do their homework and continue their education with more effort and seriousness, which will lead to their academic buoyancy and high motivates and interests them to study and affects their academic performance and lead them to progress in education.

In addition to the findings, the present study also had some limitations. One of the limitations of the present study is that due to the correlational nature of the research, caution should be exercised in causal inference. Considering that the present study has been performed on high school students in Fasa, the results obtained apply to the same community and in generalizing the results to other age and educational groups, caution should be exercised and observed. Self-reporting tools were used to collect data from students and parents, which should be considered as a limitation of self-reporting tools. The results of the present study, like many other studies, may encourage participants to use socially validated methods due to the use of self-report tools instead of studying actual behavior. Also, due to the study of several variables in this study and the simultaneous implementation of questionnaires and its time-consuming, it increased the incidence of fatigue in students.

We suggest that to better understand and better understand individual and environmental factors as well as cultural and social factors, variables such as religion, self-regulation, and parental resilience should be considered in future research. We suggest that in future research, students in other academic courses and separated based on sex be examined. Also, we suggest that interested researchers study demographic variables such as sex, age, socio-economic status, and household income concerning the proposed research model.

Declaration of Conflicting Interests: The author(s) declared no potential conflicts of interest with respect to the research, authorship, and/or publication of this article.

Funding: The authors received no financial support for the research, authorship, and/or publication of this article.

Acknowledgements: We are grateful to all the participants who have contributed to this study.

\section{References}

Bauer, K. W., \& Liang, Q. (2003). The effect of personality and precollege characteristics on first-year activities and academic performance. Journal of college student development, 44(3), 277-290.

Chamorro-Premuzic, T., \& Furnham, A. (2003). Personality traits and academic examination performance. European journal of Personality, 17(3), 237-250.

Collie, R. J., Martin, A. J., Bottrell, D., Armstrong, D., Ungar, M., \& Liebenberg, L. (2017). Social support, academic adversity and academic buoyancy: a person-centred analysis and implications for academic outcomes. Educational Psychology, 37(5), 550-564.

Colmar, S., Liem, G. A. D., Connor, J., \& Martin, A. J. (2019). Exploring the relationships between academic buoyancy, academic self-concept, and academic performance: a study of mathematics and reading among primary school students. Educational Psychology, 39(8), 1068-1089.

Dortaj, F., Mousavi, H., \& Rezaei, P. (2013). Exam anxiety and its relationship with demographic factors 
among new students in Hormozgan University of Medical Sciences. Hormozgan Medical Journal, 17(4), 365-374.

Galla, B. M., Wood, J. J., Tsukayama, E., Har, K., Chiu, A. W., \& Langer, D. A. (2014). A longitudinal multilevel model analysis of the within-person and between-person effect of effortful engagement and academic self-efficacy on academic performance. Journal of School Psychology, 52(3), 295-308.

Ghorbani, E., Zahrakar, K., \& Mohsenzadeh, F. (2020). The effectiveness of rational emotive behavior therapy-based education in students' academic burnout and buoyancy. PSYCHOLOGY AND EDUCATION, 57(2), 95-100.

Hakimi, S., Hejazi, E., \& Lavasani, M. G. (2011). The relationships between personality traits and students' academic achievement. Procedia-Social and Behavioral Sciences, 29, 836-845.

Hazrati-Viari, A., Rad, A. T., \& Torabi, S. S. (2012). The effect of personality traits on academic performance: The mediating role of academic motivation. Procedia-Social and Behavioral Sciences, 32, 367-371.

Jahedizadeh, S., Ghonsooly, B., \& Ghanizadeh, A. (2019). Academic buoyancy in higher education. Journal of Applied Research in Higher Education.

Joshanloo, M., Daemi, F., Bakhshi, A., Nazemi, S., \& Ghafari, Z. (2010). Construct validity of NEO-personality inventory-revised in Iran. Iranian Journal of Psychiatry and Clinical Psychology, 16(3), 220-230.

MacCann, C., Jiang, Y., Brown, L. E., Double, K. S., Bucich, M., \& Minbashian, A. (2020). Emotional intelligence predicts academic performance: A meta-analysis. Psychological Bulletin, 146(2), 150.

Martin, A. J. (2013). Academic buoyancy and academic resilience: Exploring 'everyday'and 'classic'resilience in the face of academic adversity. School Psychology International, 34(5), 488-500.

Martin, A. J. (2014). Academic buoyancy and academic outcomes: Towards a further understanding of students with attention $\square$ deficit/hyperactivity disorder (ADHD), students without ADHD, and academic buoyancy itself. British Journal of Educational Psychology, 84(1), 86-107.

Martin, A. J., Colmar, S. H., Davey, L. A., \& Marsh, H. W. (2010). Longitudinal modelling of academic buoyancy and motivation: Do the 5Cs hold up over time? British Journal of Educational Psychology, 80(3), 473-496.

Martin, A. J., \& Marsh, H. W. (2009). Academic resilience and academic buoyancy: Multidimensional and hierarchical conceptual framing of causes, correlates and cognate constructs. Oxford Review of Education, 35(3), 353-370.

Martin, A. J., \& Marsh, H. W. (2020). Investigating the reciprocal relations between academic buoyancy and academic adversity: Evidence for the protective role of academic buoyancy in reducing academic adversity over time. International Journal of Behavioral Development, 44(4), 301-312.

Mayer, J. D. (2007). Asserting the definition of personality. The online newsletter for personality science, 1(1), $1-4$.

Miller, S., Connolly, P., \& Maguire, L. K. (2013). Wellbeing, academic buoyancy and educational achievement in primary school students. International Journal of Educational Research, 62, 239-248.

Motowidlo, S. J., Hooper, A. C., \& Jackson, H. L. (2006). Implicit policies about relations between personality traits and behavioral effectiveness in situational judgment items. Journal of Applied Psychology, 91(4), 749.

Poropat, A. E. (2014). A meta $\square$ analysis of adult $\square$ rated child personality and academic performance in prima- 
ry education. British Journal of Educational Psychology, 84(2), 239-252.

Putwain, D. W., Connors, L., Symes, W., \& Douglas-Osborn, E. (2012). Is academic buoyancy anything more than adaptive coping? Anxiety, Stress \& Coping, 25(3), 349-358.

Putwain, D. W., \& Daly, A. L. (2013). Do clusters of test anxiety and academic buoyancy differentially predict academic performance? Learning and Individual Differences, 27, 157-162.

Putwain, D. W., Daly, A. L., Chamberlain, S., \& Sadreddini, S. (2016). 'Sink or swim': buoyancy and coping in the cognitive test anxiety-academic performance relationship. Educational Psychology, 36(10), 1807 1825.

Putwain, D. W., Wood, P., \& Pekrun, R. (2020). Achievement emotions and academic achievement: Reciprocal relations and the moderating influence of academic buoyancy. Journal of Educational Psychology.

Rezaei Gazki, P., Delavar, A., \& Samavi, A. (2019). Does Academic Commitment Affect the Learners' Progress through Academic Buoyancy? A Structural Equation Model. Iranian Evolutionary and Educational Psychology Journal, 1(3), 196-203.

Walters, C., \& Pintrich, P. PR (2001) Contextual differences in student motivation and self-regulated learning in mathematics, english and social studies classrooms. Metacognition in Learning and Instruction: Theory, Research and Practice, 103-124. 